\title{
GMR
}

\section{Sub-lethal doses of neonicotinoid and carbamate insecticides reduce the lifespan and alter the expression of immune health and detoxification related genes of honey bees (Apis mellifera)}

\author{
Hassan Tarek ${ }^{1}$, Mollah Md. Hamiduzzaman ${ }^{1}$, Nuria Morfin ${ }^{1,2}$ and Ernesto Guzman- \\ Novoa $^{1}$ \\ ${ }^{1}$ School of Environmental Sciences, University of Guelph, 50 Stone Road East, \\ Guelph, N1G 2W1, Ontario, Canada. \\ ${ }^{2}$ School of Environmental Sciences, University of Guelph, 50 Stone Road East, \\ Guelph, N1G 2W1, Ontario, Canada. \\ Corresponding author: Nuria Morfin \\ E-mail: nmorfinr@uoguelph.ca
}

Genet. Mol. Res. 17 (2): gmr16039908

Received March 09, 2018

Accepted April 23, 2018

Published April 27, 2018

DOI: http://dx.doi.org/10.4238/gmr16039908

Copyright $@ 2018$ The Authors. This is an open-access article distributed under the terms of the Creative Commons Attribution ShareAlike (CC BY-SA) 4.0 License.

\begin{abstract}
Honey bees (Apis mellifera) are exposed to sublethal doses of insecticides, but little is known about insecticide effects on their survivorship associated to health-related gene expression. To test the effect of sublethal doses of clothianidin, imidacloprid and carbaryl on the lifespan and health of honey bees, workers were orally and topically exposed to LD5 doses of these insecticides. The survivorship of treated bees was monitored and the expression of three immune-related genes, hymenoptaecin (AmHym), basket (AmBask) and lysozyme (AmLyso2) was analyzed at 24 and 72 hours post treatment (hpt), as well as that of the antioxidant-related gene vitellogenin (AmVit2), the poly-U binding factor (AmPuf68), and the detoxification gene cytochrome P450 (AmCYP9Q3). The three insecticides significantly reduced the length of life of bees but the mode of application did not affect survivorship. AmHym, AmBask and AmVit2 expression was significantly down-regulated at $72 \mathrm{hpt}$ in bees treated with clothianidin and imidacloprid, indicating immunosuppression. However, AmLyso2, AmCYP9Q3 and AmPuf68 were significantly up-regulated. The down-regulation of AmVit2 could have caused decreased resistance to oxidative stress. AmPuf68 expression could be associated with increased protection against xenobionts. AmCYP9Q3 was up-regulated at 24 and $72 \mathrm{hpt}$
\end{abstract}


in oral exposures, but only until $72 \mathrm{hpt}$ in topical exposures, indicating faster sensitivity towards detoxification mechanisms in oral treatments. This study demonstrated detrimental effects of sublethal doses of clothianidin, imidacloprid and carbaryl on honey bee survivorship, immunity and antioxidant mechanisms, and an induction of defense and detoxification responses that could be physiologically costly to the bees.

Key words: Honey bees; Neonicotinoid insecticides; Carbamates; Sublethal exposure; Immunity; Gene expression

\section{INTRODUCTION}

A decline in abundance and diversity of wild bees as well as honey bees (Apis mellifera) has been recently reported from several regions of the world (Potts et al., 2010). The magnitude of this pollinator crisis is believed to not only have a deep impact on agriculture and its related economy but also on plant diversity. For honey bees in particular, massive losses of colonies have been termed Colony Collapse Disorder (CCD) (Kevan et al., 2007). Parasites and pesticides are among the factors most frequently associated with honey bee colony mortality (Guzman-Novoa, 2016). For pesticides specifically, neonicotinoids insecticides are frequently blamed for honey bee colony loses (Van der Sluijs et al., 2013), but many other insecticides are commonly used in managed ecosystems that may have an impact on honey bee health, such as carbamates (Johnson et al., 2010). Traditionally, measurement of the damage by pesticides to honey bees has relied largely on the determining their toxicity level by estimating their lethal dose $\left(\mathrm{LD}_{50}\right)$. However, estimations of lethal doses may only be a partial measure of the deleterious effects of pesticides. In addition to direct mortality caused by the acute toxicity of pesticides, their sublethal effects on bees' physiology and behavior must be considered for a more comprehensive analysis of their impact. The role of pesticides in honey bee colony losses, with their sublethal effects, has recently regained consideration (Mullin et al., 2010). For example, sublethal levels of neonicotinoids have been shown to impair the learning abilities of honey bees and to possibly inhibit their immune systems (Blacquièrie et al., 2012).

A considerable number of genes of the immune system in honey bees have been identified. The honey bee immune system has been found to be very similar to that of Drosophila and the same signaling pathways found in Drosophila are also at work in A. mellifera (Evans, 2006). However, not much is known about how sublethal exposure to different classes of insecticides affect the expression of immune, health and detoxification related genes in the exposed bees. It is likely that exposure to sublethal doses of pesticides might impair the bees' immune, antioxidant and detoxification systems. As a result, bees might not be able to defend themselves from parasites and diseases or could be stressed out, leading to early mortality. Alaux et al. (2010) found physiological evidence that sublethal doses of imidacloprid and the parasitic microsporidian Nosema can interact synergistically to affect bee health negatively, including physiological changes initiated by sublethal dose exposure that decreased bee tolerance toward Nosema infection.

The objectives of this study were to determine the effects of sublethal doses of three widely used insecticides that have been associated with cases of CCD, clothianidin, imidacloprid and carbaryl, on honey bee survivorship and gene expression related to immunity, antioxidant processes, longevity and detoxification. The immune related genes chosen were hymenoptaecin (AmHym), lysozyme (AmLyso2) and basket (AmBask) (Evans, 2006). Vitellogenin (AmVit2) was selected because it is associated with antioxidant processes and longevity (Amdam et al., 2004) and the poly-U binding factor $68 \mathrm{kDa}$ (AmPuf68) linked to pre-mRNA splicing and stem cell proliferation (Wang et al., 2013), was included as health-related gene. Cytochrome P450 (AmCYP9Q3) (Mao et al., 2011), was selected as detoxification gene.

\section{MATERIALS AND METHODS}

\section{Honey bee sources}

Experiments were conducted at the University of Guelph's Honey Bee Research Center in Ontario, Canada. Honey bee colonies containing queens of the Buckfast strain were used as a source of workers. The colonies were free of brood diseases and were not treated to control parasitic mites prior to the experiments because they 
Sub-lethal doses of neonicotinoid and carbamate insecticides reduces the lifespan and alters the expression of immune, health and detoxification related genes of honey bees (Apis mellifera)

had very low levels of $V$. destructor infestation $(<1 \%)$. To obtain worker bees of the same age, frames of capped brood from the source hives were incubated at $32 \pm 2{ }^{\circ} \mathrm{C}$ and $50 \pm 10 \% \mathrm{RH}$ overnight in emergence cages $(50 \times$ $7 \times 25 \mathrm{~cm}$ ). After $24 \mathrm{~h}$, the newly emerged bees were immediately used for the experiments.

\section{Insecticides}

Three insecticides of technical analytical grade (purity >99\%), imidacloprid (1-(6chloro-3-pyridylmethyl)-Nnitroimidazolidin-2-ylideneamine), clothianidin (1-(2-chloro-1, 3-thiazol-5-ylmethyl)-3-methyl-2nitroguanidine), and carbaryl (1-naphthyl-N-methyl carbamate), were obtained from Sigma-Aldrich (Oakville, Ontario, Canada). Pesticides were dissolved with sterile $\mathrm{dH}_{2} \mathrm{O}$ to prepare stock solutions $(1000 \mathrm{ng} / \mu \mathrm{l}$; pesticide/solvent). To prepare the doses for oral treatments, the stock solutions were diluted in serial dilutions of $50 \%$ sucrose syrup. For the doses of contact application, the serial dilutions were made with sterile $\mathrm{dH}_{2} \mathrm{O}$.

\section{Experiment 1: Effect of sub-lethal doses of insecticides on the survivorship of honey bees}

Worker bees were challenged orally and topically with sublethal doses of clothianidin, imidacloprid, and carbaryl. In previous studies, sublethal doses of pesticides tested were $5 \times 10^{0}$ to $1.5 \times 10^{2}$ times lower than their $\mathrm{LD}_{50 \text { s }}$ (Decourtye et al., 2004; Aliouane et al., 2009), or the $\mathrm{LD}_{5}, \mathrm{LD}_{10}$ and $\mathrm{LD}_{25}$ values (Mackenzie and Winston, 1988). Based on that range of options, in the current study, $\mathrm{LD}_{5}$ was selected for the sublethal dose to be tested (Table 1). Preliminary studies were conducted to determine $\mathrm{LD}_{5}$ for the three insecticides (Tarek $\mathrm{H}$, Hamiduzzaman MM, Morfin N and Guzman-Novoa E, Unpublished results).

For oral exposure, newly emerged bees were food deprived for $2 \mathrm{~h}$ before administering the insecticides. After that time, each bee was individually fed $10 \mu \mathrm{l}$ of $50 \%$ sucrose solution containing a sublethal dose of one of the insecticides $\left(\mathrm{LD}_{5}\right)$ with the aid of a micropipette (Eppendorf, Mississauga, Ontario, Canada) until 30 bees had been fed. Table 1 shows the actual doses of each insecticide received by the bees. Control bees received only 10 $\mu \mathrm{l}$ of $50 \%$ sucrose syrup. After consuming the solution, each group of 30 bees per treatment was placed in a wooden cage $(12.7 \times 8.5 \times 14.5 \mathrm{~cm})$ with a $3 \mathrm{mesh} / \mathrm{cm}$ wire screened wall on both sides. The cage was kept at an incubator $\left(32 \pm 2{ }^{\circ} \mathrm{C}, 50 \pm 10 \% \mathrm{RH}\right)$ and the bees were provided with two gravity feeders, one containing 20 $\mathrm{ml}$ of a $50 \%$ sucrose solution, and the other containing $\mathrm{dH}_{2} \mathrm{O}$; the bees were permitted to feed ad libitum.

For topical exposure, $2 \mu \mathrm{l}$ of each insecticide solution in $\mathrm{dH}_{2} \mathrm{O}$ containing the sublethal dose were administered individually as a single application on the dorsal surface of a worker's thorax using a micropipette. Control bees only received $2 \mu \mathrm{l}$ of $\mathrm{dH}_{2} \mathrm{O}$. Treated bees were kept in wooden cages as described above.

Treated bees in the cages were observed until all of them died. The number of live and dead bees were recorded at days $0,7,14,21,27,33,35,37,39$ and 41, and percentages of surviving bees for those days were calculated. Median survival times (MST) of honey bee workers were also calculated using Probit analysis. Three replications per treatment per insecticide were conducted.

Table 1. Sub-lethal doses $\left(\mathrm{LD}_{5}\right)$ in ng/bee and median survival time (MST) in days for honey bee workers that were treated orally or topically with three insecticides. Values were calculated by Probit analysis. Treatments with nonoverlapping confidence intervals are considered significantly different.

\begin{tabular}{|c|c|c|c|}
\hline Application mode & Treatment & $\mathrm{LD}_{5} \operatorname{dose}^{*}\left(95 \% \mathrm{CL}^{* *}\right)$ & $\operatorname{MST}\left(95 \% \mathrm{CL}^{* *}\right)$ \\
\hline \multirow[t]{4}{*}{ Oral } & Control & 0.00 & $30(29.6-31.3)$ \\
\hline & Imidacloprid & $39.5(46.6-29.2)$ & $21(20.2-22.5)$ \\
\hline & Clothianidin & $0.63(0.71-0.59)$ & $26(25.2-26.8)$ \\
\hline & Carbaryl & $205.0(212-196)$ & $28(24.5-29.4)$ \\
\hline \multirow[t]{2}{*}{ Contact } & Control & 0.00 & $30(29.1-31.9)$ \\
\hline & Imidacloprid & $27.7(36.5-21.7)$ & $27(26.2-28.6)$ \\
\hline
\end{tabular}




\begin{tabular}{lcc} 
Clothianidin & $14.7(21.3-9.8)$ & $25(24.5-26.7)$ \\
\hline Carbaryl & $112.0(119-107)$ & $23(21.2-23.7)$
\end{tabular}

(Note: ${ }^{*}$ Actual doses received by individual bees; ${ }^{* *}$ CL: Confidence Limits)

\section{Experiment 2: Gene expression in honey bees exposed to sublethal doses of insecticides}

The expression level of three immune related genes, two health-related genes and one detoxification gene (Table 2) was measured in worker bees at 0,24 and 72 hours post treatment (hpt) after orally and topically exposing adult bees as described above to the $\mathrm{LD}_{5}$ doses of the three insecticides (Table 1). For each treatment, 15 workers were obtained from incubating cages and placed in groups of three individuals within each of five, $2 \mathrm{ml}$ eppendorf tubes (Eppendorf, Mississauga, Ontario, Canada). Similarly, untreated bees were collected as a control. Collected samples were stored immediately at $-70^{\circ} \mathrm{C}$ until analysis.

Table 2. Primers used for amplification of the target and reference control genes.

\begin{tabular}{|c|c|c|c|c|}
\hline Gene product & $\begin{array}{l}\text { Gene } \\
\text { designation }\end{array}$ & Primer sequence (5' - 3') & $\begin{array}{l}\text { Product } \\
\text { length }\end{array}$ & Source \\
\hline Hymenoptaecin & AmHym* & $\begin{array}{l}\text { F: CTCTTCTGTGCCGTTGCATA } \\
\text { R: GCGTCTCCTGTCATTCCATT }\end{array}$ & $200 \mathrm{bp}$ & Evans (2006) \\
\hline Basket & AmBask* & $\begin{array}{l}\text { F: AGGAGAACGTGGACATTTGG } \\
\text { R: AATCCGATGGAAACAGAACG }\end{array}$ & $243 \mathrm{bp}$ & Evans (2006) \\
\hline Vitellogenin & AmVit $2 *$ & $\begin{array}{l}\text { F: ACGACTCGACCAACGACTT } \\
\text { R: AACGAAAGGAACGGTCAATTCC }\end{array}$ & 494 bp & Guidugli et al. (2005) \\
\hline $\begin{array}{l}\text { poly-U-binding factor } 68 \\
\mathrm{kDa}\end{array}$ & AmPuf68* & $\begin{array}{l}\text { F: CAAGACCTCCAACTAGCATG } \\
\text { R: CAACAGGTGGTGGTGGTG }\end{array}$ & $201 \mathrm{bp}$ & $\begin{array}{l}\text { Hamiduzzaman et al. } \\
\text { (2012) }\end{array}$ \\
\hline Ribosomal Protein S5 & $\operatorname{RpS5**}$ & $\begin{array}{l}\text { F: AATTATTTGGTCGCTGGAATTG } \\
\text { R: TAACGTCCAGCAGAATGTGGTA }\end{array}$ & $115 \mathrm{bp}$ & Evans (2006) \\
\hline $\begin{array}{l}\text { Glyceraldehyde 3- } \\
\text { phosphate dehydrogenase2 }\end{array}$ & GAPD2** & $\begin{array}{l}\text { F: GATGCACCCATGTTTGTTTG } \\
\text { R: TTTGCAGAAGGTGCATCAAC }\end{array}$ & 203 bp & Thompson et al. (2007) \\
\hline
\end{tabular}

(Note: F, Forward primer and R, Reverse primer. * Target and ** Reference control genes).

\section{RNA extraction and cDNA synthesis}

Total RNA was extracted by homogenizing five frozen bees per sample in extraction buffer as per Chen et al. (2000). The homogenates were extracted twice with chloroform, and the RNA was precipitated using LiCl. The amount of total RNA extracted was determined with a spectrophotometer (Nanovue GE Healthcare, Cambridge, UK). For cDNA synthesis, $2 \mu \mathrm{g}$ of total RNA was reverse-transcribed using Oligo (dT)18 and M-MuLV RT with the RevertAidTM H Minus First Strand cDNA Synthesis Kit (Fermentas Life Sciences, Burlington, Ontario), following the instructions of the manufacturer. 
Sub-lethal doses of neonicotinoid and carbamate insecticides reduces the lifespan and alters the expression of immune, health and detoxification related genes of honey bees (Apis mellifera)

\section{PCR reactions}

All PCR reactions were done with a Mastercycler (Eppendorf, Mississauga, Ontario, Canada). Each $15 \mu$ of reaction contained $2 \mu \mathrm{l}$ of cDNA, $1.5 \mu \mathrm{l}$ of 10X PCR buffer (New England BioLabs, Pickering, Ontario), $0.5 \mu \mathrm{l}$ of $10 \mathrm{mM}$ dNTPs (deoxynucleoside triphosphates) (Bio Basic Inc., Markham, Ontario), 0.25-2 $\mu$ l of forward and reverse primers for the honey bee ribosomal protein, RpS5 as reference gene, or glyceraldehydes-3phosphate dehydrogenase 2 (GAPD2) (Thompson et al., 2007) and 1.5-2 $\mu \mathrm{l}$ of each primer for the target gene. Additionally, the reaction contained $0.2 \mu \mathrm{l}$ of $5 \mathrm{U} / \mu \mathrm{l}$ Taq polymerases, and 5.3-7.3 $\mu$ l of sterile $\mathrm{dH}_{2} \mathrm{O}$ to adjust the final volume. RpS5 was used as reference gene with AmHym, AmBask, AmLyso2, and AmPuf68. GAPD2 was used as reference gene with AmVit2 and AmCYP9Q3. Primers sequences are listed in Table 2. Amplification conditions for AmHym, AmBask, AmLyso 2 and AmPuf 68 were $94^{\circ} \mathrm{C}$ for 3 min, followed by 35 denaturing cycles at $94^{\circ} \mathrm{C}$ for $30 \mathrm{~s}$, annealing at $55^{\circ} \mathrm{C}$ for $60 \mathrm{~s}$ and $60 \mathrm{~s}$ at $72^{\circ} \mathrm{C}$, and a final extension step at $72^{\circ} \mathrm{C}$ for $10 \mathrm{~min}$. Amplification conditions for $A m V i t 2$ and $A m C Y P 9 Q 3$ were the same, except that the annealing temperature was $58^{\circ} \mathrm{C}$.

\section{Separation and semi-quantification of PCR products}

PCR products were separated by electrophoresis in $1.1 \%$ agarose gels and stained with ethidium bromide. A 100 bp DNA ladder (Bio Basic Inc., Markham, Ontario) was used to identify the size of the amplicons. The intensity of the amplified bands was measured in pixels using the Scion Image (Scion Corporation, Frederick, MD, USA) as per Dean et al. (2002). The ratio of band intensity between the target gene and the reference gene was calculated to determine relative expression units (REUs) according to Hamiduzzaman et al. (2012). A similar ratio of band intensity between the target gene and the reference gene was observed in all samples. To determine whether quantification at 35 amplification cycles was not affected by signal saturation of the band intensities, randomly selected samples with high, medium and low REUs were also quantified in the same manner with fewer amplification cycles, and the pattern of expression based on the REU values were not significantly different when 25,30 and 35 amplification cycles were used $\left(F_{2,15}=0.30, p=0.75\right)$. Thus, we chose to analyze results at 35 cycles because in most cases the relationship between the number of cycles and molecules is relatively linear at 35 cycles when semi-quantitative RT-PCR is used, which provides high amplification efficiency.

\section{Statistical analysis}

The percent bee mortality caused by the insecticides tested was calculated for the various time points and the data were arcsine square root transformed and subjected to analysis of variance (ANOVA). The median survival time values were determined by Probit analysis using the US Environmental Protection Agency Statistical Program, version 1.5 (USEPA, 1992). Gene expression data of the three insecticides at 24 and 72 hpt were analyzed by ANOVA. These procedures were performed with the package IBM-SPSS v. 23 (SPSS Inc., Chicago, IL, USA).

\section{RESULTS}

\section{Effect of sub-lethal doses of insecticides on honey bee survivorship}

The three insecticides significantly reduced the length of life of exposed bees compared with control bees $\left(\mathrm{F}_{3}\right.$, $\left.{ }_{232}=7.49, \mathrm{P}<0.0001\right)$, but no differences were found between insecticides for this variable. The mode of application did not affect bee survivorship $\left(\mathrm{F}_{1,232=} 0.89, \mathrm{P}=0.35\right)$ and no significant interactions were detected

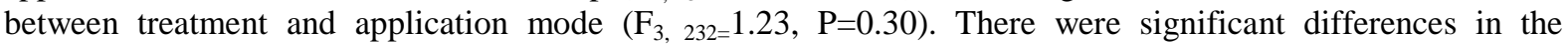

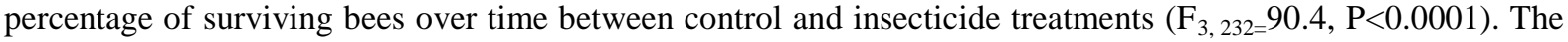
cumulative mortality rate increased with time in all experimental groups until day 39 , which was the day when the last treated bee died; some control bees remained alive until day 41 (Figure 1). Additionally, the $\mathrm{LD}_{5} \mathrm{doses}$ of the three insecticides significantly reduced the MST of treated bees compared to the MST of control bees (Table 1). 


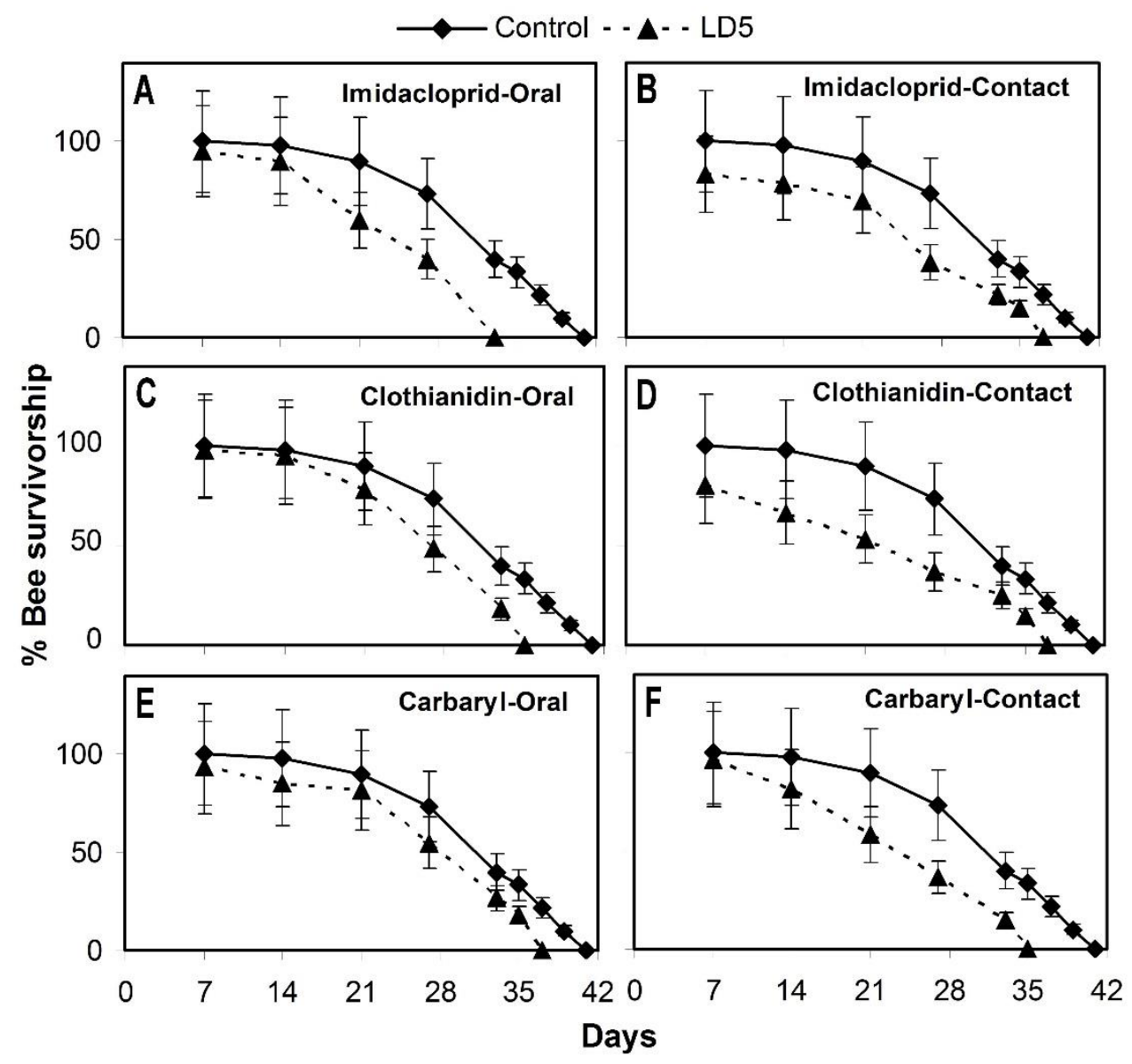

Figure 1. Mean percentage ( \pm SE) of surviving bees over time (days) after exposure to sublethal doses (LD5) of three insecticides: A) imidacloprid orally-treated bees, B) imidacloprid topically-treated bees, C) clothianidin orally-treated bees, D) clothianidin topically-treated bees, E) carbaryl orally-treated bees, F) carbaryl topically-treated bees. Control bees were not exposed to insecticides and three repetitions of 20 bees were conducted for each treatment.

\section{Immune related gene expression}

For control and carbaryl treatments, the expression of AmHym was similar at $24 \mathrm{hpt}$. However, for imidacloprid and clothianidin treated bees, the expression of AmHym was significantly higher than that of control bees at 24 hpt in both oral $\left(\mathrm{F}_{(3,20)}=28.67, \mathrm{P}<0.0001\right.$; Figure $\left.2 \mathrm{~A}\right)$ and contact exposures $\left(\mathrm{F}_{(3,20)}=52.54, \mathrm{P}<0.0001\right.$; Figure $\left.2 \mathrm{~B}\right)$. At 72 hpt, again, AmHym expression of control bees did not change from that observed at 24 hpt for both exposure modes, but relative to the control treatment, the expression of this gene was significantly downregulated in clothianidin and imidacloprid treated bees. AmHym expression in the carbaryl treatment did not change at $72 \mathrm{hpt}$ when bees were treated orally but was significantly up-regulated when the bees were treated topically $\left(\mathrm{F}_{(3,20)}=25.65, \mathrm{P}<0.0001 ; \mathrm{F}_{(3,20)}=185.64, \mathrm{P}<0.0001\right.$, respectively; Figures $2 \mathrm{~A}$ and $\left.2 \mathrm{~B}\right)$.

For control and carbaryl treatments, the expression of AmBask was similar at 24 hpt. However, for imidacloprid and clothianidin treated bees, the expression of AmBask was significantly higher than that of control bees at 24 hpt in both oral $\left(\mathrm{F}_{(3,20)}=14.93, \mathrm{P}<0.0001\right.$; Figure $\left.2 \mathrm{C}\right)$ and contact exposures $\left(\mathrm{F}_{(3,20)}=34.96, \mathrm{P}<0.0001\right.$; Figure $\left.2 \mathrm{D}\right)$. At $72 \mathrm{hpt}$, again, AmBask expression of control bees did not change from that observed at 24 hpt for both exposure modes, but relative to the control treatment, the expression of this gene was significantly downregulated in clothianidin and imidacloprid treated bees. AmBask expression in the carbaryl treatment decreased significantly at $72 \mathrm{hpt}$ when bees were treated orally but did not change when bees were treated topically $\left(\mathrm{F}_{(3,20)}=10.56, \mathrm{P}<0.0001, \mathrm{~F}_{(3,20)}=4.95, \mathrm{P}=0.010\right.$, respectively; Figures $2 \mathrm{C}$ and $\left.2 \mathrm{D}\right)$.

The expression of AmLyso2 did not differ among treatments at $24 \mathrm{hpt}$ in both oral $\left(\mathrm{F}_{(3,20)}=2.23, \mathrm{P}=0.116\right)$ and contact applications $\left(\mathrm{F}_{(3,20)}=0.70, \mathrm{P}=0.561\right.$; Figures $2 \mathrm{E}$ and $\left.2 \mathrm{~F}\right)$. At $72 \mathrm{hpt}$, AmLyso2 expression of control bees 
did not change from that observed at $24 \mathrm{hpt}$ for both exposure modes, but the expression of this gene was significantly up-regulated in clothianidin and imidacloprid treated bees. AmLyso2 expression in the carbaryl treatment increased significantly at $72 \mathrm{hpt}$ when bees were treated orally but did not change when bees were treated topically $\left(\mathrm{F}_{(3,20)}=35.45, \mathrm{P}<0.0001, \mathrm{~F}_{(3,20)}=4.16, \mathrm{P}=0.019\right.$, respectively; Figures $2 \mathrm{E}$ and $\left.2 \mathrm{~F}\right)$.

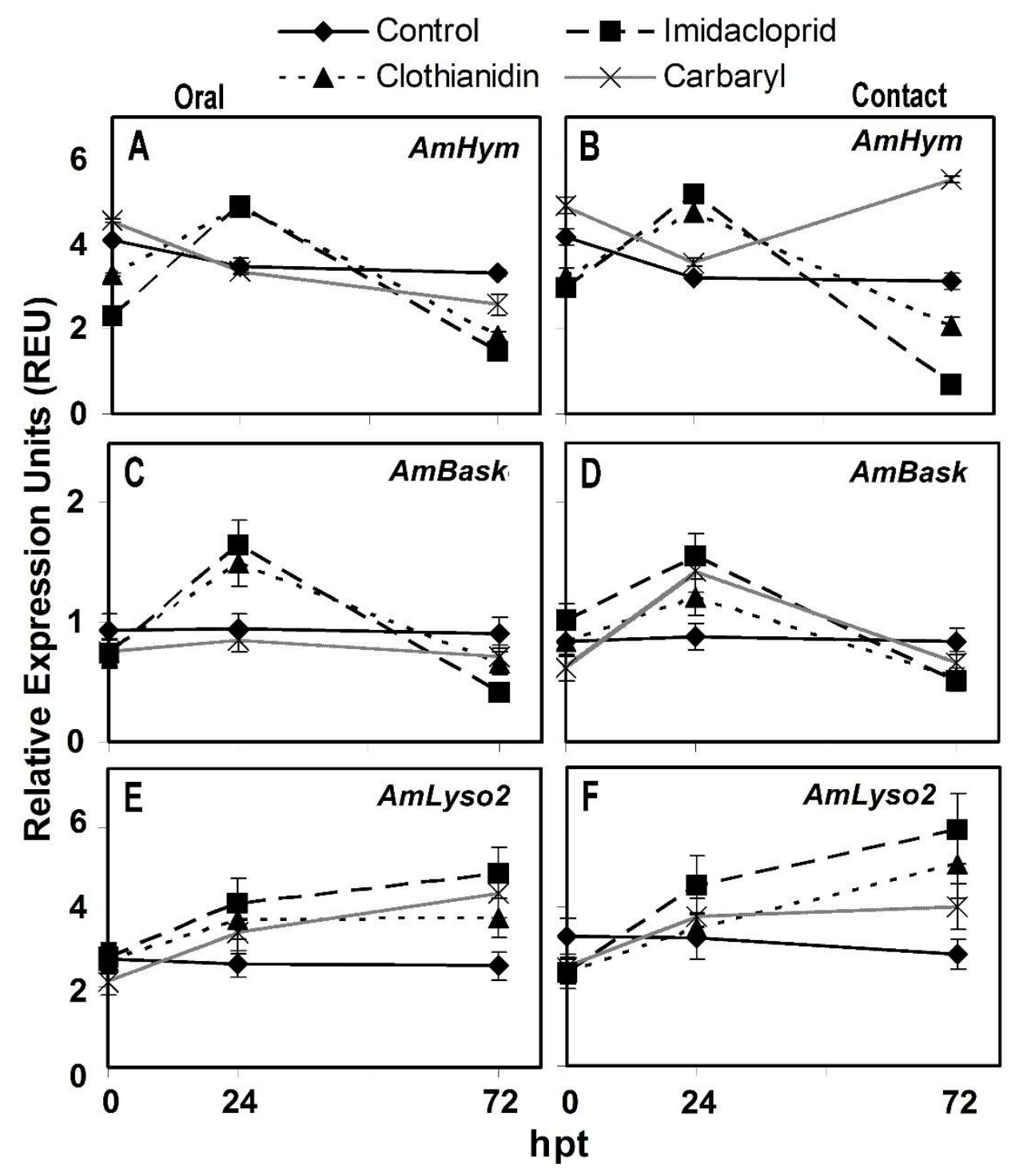

Figure 2. Mean relative expression units (REU $\pm \mathrm{SE}$ ) of immune related genes in worker bees treated orally or topically with sublethal doses (LD5) of three insecticides from 0 to 72 hours post treatment (hpt): A) AmHym for orally-treated bees, B) AmHym for topically-treated bees, C) AmBask for orally-treated bees, D) AmBask for topically-treated bees, E) AmLyso2 for orally-treated bees, F) AmLyso 2 for topically-treated bees. Control bees were not exposed to insecticides and three repetitions of 20 bees were conducted for each treatment.

\section{Health and detoxification related gene expression}

For control and carbaryl treatments, the expression of AmVit2 was similar at $24 \mathrm{hpt}$. However, for imidacloprid and clothianidin treated bees, the expression of AmVit 2 was significantly higher than that of control bees in both oral $\left(\mathrm{F}_{(3,20)}=4.77, \mathrm{P}=0.011\right.$; Figure $\left.3 \mathrm{~A}\right)$ and contact exposures $\left(\mathrm{F}_{(3,20)}=10.53, \mathrm{P}<0.0001\right.$; Figure $\left.3 \mathrm{~B}\right)$. At $72 \mathrm{hpt}$, AmVit2 expression of control bees did not change from that observed at $24 \mathrm{hpt}$ for both exposure modes, but relative to the control treatment, the expression of this gene was significantly down-regulated in clothianidin and imidacloprid treated bees. However, AmVit2 expression in the carbaryl treatment increased significantly at 72 hpt when the bees were treated topically $\left(\mathrm{F}_{(3,20)}=27.46, \mathrm{P}<0.0001\right.$; Figure $\left.3 \mathrm{~B}\right)$. 
The expression of AmPuf68 was significantly up-regulated at $24 \mathrm{hpt}$ for the oral application in imidacloprid treated bees compared to the other treatments $\left(\mathrm{F}_{(3,20)}=64.54, \mathrm{P}<0.0001\right.$; Figure 3C). However, for the contact application, the expression of AmPuf68 was significantly higher in imidacloprid, clothianidin and carbaryl treated bees than in control bees $\left(\mathrm{F}_{(3,20)}=42.90, \mathrm{P}<0.0001\right.$; Figure 3D). At $72 \mathrm{hpt}$, AmPuf68 expression of control bees did not change from that observed at $24 \mathrm{hpt}$ for both exposure modes, but it was significantly up-regulated in clothianidin, imidacloprid and carbaryl treated bees $\left(\mathrm{F}_{(3,20)}=44.13, \mathrm{P}<0.0001, \mathrm{~F}_{(3,20)}=213.12, \mathrm{P}<0.0001\right.$, respectively; Figures $3 \mathrm{C}$ and $3 \mathrm{D})$.

The bees orally treated with the three insecticides showed significant up-regulation of $A m C Y P 9 Q 3$ at 24 hpt, with the highest expression observed in carbaryl treated bees $\left(\mathrm{F}_{(3,20)}=146.48, \mathrm{P}<0.0001\right.$; Figure 3E). However, the expression of this gene did not differ among treatments at $24 \mathrm{hpt}$ for contact applications $\left(\mathrm{F}_{(3,20)}=0.66\right.$, $\mathrm{P}=0.586$; Figure $3 \mathrm{~F})$. At $72 \mathrm{hpt}$, AmCYP9Q3 expression of control bees did not change from that observed at 24 hpt for both exposure modes, but the expression of this gene was significantly up-regulated in imidacloprid, clothianidin and carbaryl treated bees for both oral and contact application treatments $\left(\mathrm{F}_{(3,20)}=133.52, \mathrm{P}<0.0001\right.$, $\mathrm{F}_{(3,20)}=40.50, \mathrm{P}<0.0001$, respectively; Figures $3 \mathrm{E}$ and $\left.3 \mathrm{~F}\right)$.

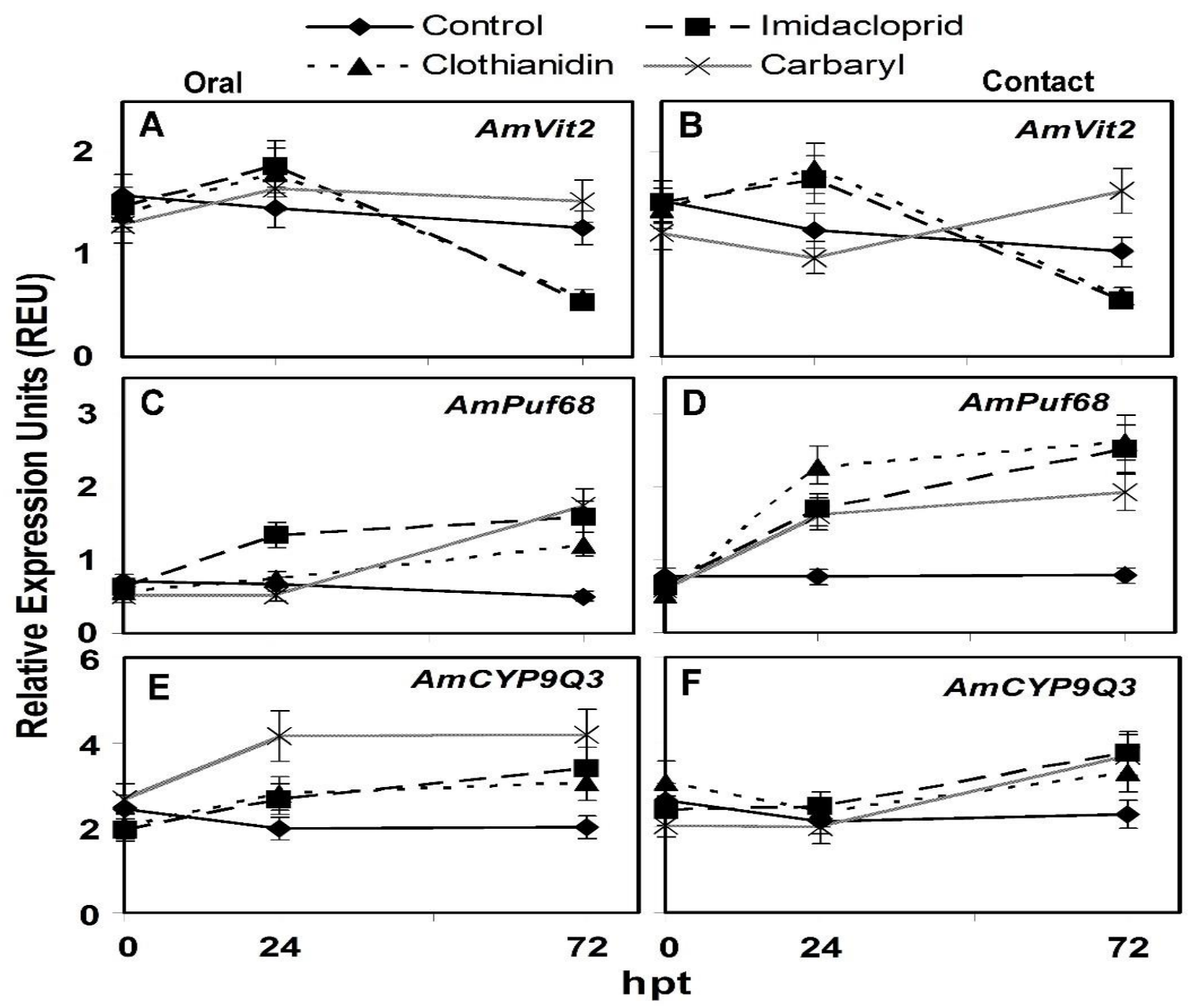

Figure 3. Mean relative expression units (REU $\pm \mathrm{SE}$ ) of health and detoxification related genes in worker bees treated orally or topically with sublethal doses $\left(\mathrm{LD}_{5}\right)$ of three insecticides from 0 to 72 hours post treatment (hpt): A) AmVit2 for orally-treated bees, B) AmVit2 for topically-treated bees, C) AmPuf68 for orally-treated bees, D) AmPuf68 for topically-treated bees, E) AmCYP9Q3 for orally-treated bees, F) $A m C Y P 9 Q 3$ for topically-treated bees. Control bees were not exposed to insecticides and three repetitions of 20 bees were conducted for each treatment. 


\section{DISCUSSION}

\section{Honey bee survivorship}

Worker bees treated orally or topically with $\mathrm{LD}_{5}$ doses of the three insecticides lived significantly less than control bees, which was measured in different ways (length of life, MST and survival over time). The length of life of treated bees decreased between 2 and $8 \mathrm{~d}$ (7-27\% reduction). These findings coincide with what has been reported in the literature for carbaryl and other insecticides. For example, bees treated with a $\mathrm{LD}_{5}$ of diazinon, carbaryl, and resmethrin lived between $7 \%$ and $25 \%$ shorter lives than control bees (Mackenzie and Winston, 1988). Also, Wu et al. (2011) found that adult longevity decreased $4 \mathrm{~d}$ in bees exposed to residues of imidacloprid, clothianidin, and aldicarb in contaminated brood comb during development, although compared to our study, Wu et al. (2011) used doses that were at least five times higher than those used by us for clothianidin and imidacloprid. López et al. (2017) reported that different pesticides, including clothianidin, could negatively affect bee survivorship, but again, these authors used doses of clothianidin 12 times higher than those used in this study. Williamson et al. (2014) observed that bees fed clothianidin suffered significantly greater mortality than control bees, but once more, the doses used in their study, were five times higher compared to this study. Therefore, this study confirms results of detrimental effects of neonicotinoids and carbaryl on the lifespan of bees, but using the lowest doses so far tested of these insecticides.

\section{Immune related gene expression}

The expression of AmHym in treated bees was significantly higher at $24 \mathrm{hpt}$ and significantly lower at $72 \mathrm{hpt}$ than that of control bees when they were treated with both neonicotinoid insecticides regardless of mode of exposure. This temporal variance in AmHym expression has been reported from other studies using biotic factors as inducers. For example, the expression of AmHym was increased within the first hour when honey bees or bumble bees were challenged with $E$. coli, but after $24 \mathrm{~h}$, the expression level of the gene was similar or lower to that of the control treatment (Erler et al., 2011). Similarly, a long-term reduction in the expression of AmHym was found when honey bees were challenged with $V$. destructor mites (Hamiduzzaman et al., 2012). Other studies of bees exposed to insecticides and pathogens have found contradictory results. For example, Collison et al. (2017) found an up-regulation of AmHym in bees treated for 2 to $168 \mathrm{~h}$ with imidacloprid and then challenged with lipopolysaccharides from E. coli. In another study, no effect on AmHym regulation was found in bees treated with thiacloprid, but a down-regulation was observed in bees exposed to the insecticide and then challenged with P. larvae (Siede et al., 2017).

The expression pattern of AmBask was almost identical to that of AmHym. AmBask transcription was significantly increased at $24 \mathrm{hpt}$ and significantly decreased at $72 \mathrm{hpt}$ for workers treated orally and topically with imidacloprid and clothianidin. To the best of our knowledge, the impact of neonicotinoid insecticides on the expression of this gene is reported for the first time. Like in the case of AmHym, similar patterns of AmBask expression have been observed when insects are challenged with biotic agents. For example, a significant downregulation of AmBask was observed within $8 \mathrm{hpt}$ when Erler et al. (2011) injected E. coli to bumble bees (B. terrestris). For abiotic factors, acaricides like thymol and coumaphos caused decreased expression of AmBask in honey bees 30 days post application of the acaricides (Boncristiani et al., 2012).

AmBask, as part of JNK signaling pathway, can activate melanization and the production of antimicrobial peptides when challenged with pathogens (Evans, 2006). Similarly, AmHym regulates the production of hymenoptaecin, an antimicrobial peptide synthesized after activation of the Toll and Imd pathways, which also leads to activation of components of the JNK signaling pathway (Broderick et al., 2009). The findings of the current study suggest that the JNK pathway might have been induced by a chemical molecule in the same manner that microorganisms induce it. Reduction in the expression of AmBask could perhaps contribute to reduced longevity of honey bees by decreasing their ability to activate immune signaling pathways and to defend themselves against pathogens through the synthesis of AMPs. Also, it is possible that the drop in expression observed in AmHym and AmBask at 72 hpt may have been due to the effect of metabolite compounds derived from the insecticides' molecules, which are produced after insecticides are metabolized. Some metabolites of imidacloprid, such as 4-hydroxy imidacloprid and olefin-imidacloprid have insecticidal properties which are distinct from those of the parent compound. For instance, olefin-imidacloprid was about 16 times more active than imidacloprid against the cotton aphid (Nauen et al., 1998). Additionally, many synthetic insecticides increase oxidative stress, and this could have severe impacts on the production of some AMPs in insects (James and $\mathrm{Xu}, 2011$ ). Therefore, metabolite compounds of neonicotinoids may act synergistically becoming more toxic. It is possible that in this study, they may have similarly affected the expression of AmHym 
and AmBask over time. It seems that initially (24 hpt), the exposed bees responded with an up-regulation of these genes to produce AMPs as a defense mechanism, but at $72 \mathrm{hpt}$, the neonicotinoid insecticides ended up suppressing the expression of the genes, which may have resulted in immunosuppression and reduced survivorship.

The pattern of expression of AmHym in bees orally treated with carbaryl was very similar to that in control bees, whereas in topical applications, the gene was up-regulated at $72 \mathrm{hpt}$ relative to the control treatment. Similarly, AmBask expression was not affected in bees treated orally with carbaryl, but responded temporarily to the insecticide in topical applications with elevated expression at $24 \mathrm{hpt}$. Clearly, carbaryl induced the activation of AmBask more by contact application than by oral ingestion, probably because of the topical nature of its mode of action (Simon, 2014). Degradation of carbaryl by detoxification enzymes could be rapid when ingested and thus, the insecticide may have been at very low levels after ingestion to induce AmBask or AmHym expression in the bees.

The up-regulation of AmLyso2 was triggered by neonicotinoid insecticides, particularly imidacloprid at $72 \mathrm{hpt}$, although a similar effect but to a lesser degree, was caused by carbaryl. The difference in up-regulation levels between neonicotinoid and carbaryl treatments in topical applications may have been due to the possibility that molecules of neonicotinoids rapidly reach their sites of action compared with the carbaryl molecule. This might have led to a faster and stronger induced activity in AmLyso2. Most insecticides are metabolized by oxidative reaction, and AmLyso2, as a cellular immune gene, is associated to phagocytosis, which involves the production of reactive oxygen species (ROS). ROS plays an important role in the oxidative reaction to insecticide toxicity (Broderick et al., 2009), which could explain differences in expression levels due to different insecticides tested. In addition, as mentioned before in this study, metabolizing neonicotinoid insecticides produce more toxic compounds, which may become an additional inducer of the gene. Despite the above differences in expression levels, all insecticides tested share in common that all up-regulated this gene to some degree. AmLyso 2 is expressed after the activation of the Imd and Toll pathways, and its activity is related to cellular responses mainly against microbes (Evans, 2006). Therefore, the up-regulation of AmLyso-2 by sublethal doses of insecticides could be associated with a transient activation of immune responses, potentially protecting bees against bacterial infections. However, the energetic cost of a triggered immune response could affect bees by limiting long term responses due to exhaustion of energy resources.

\section{Health and detoxification related gene expression}

Responses of health and detoxification related genes differed with the type of insecticide bees were exposed to. AmVit2 responded to neonicotinoid exposure similarly to AmHym and AmBask, for both, oral and contact applications. That is, there was a transient up-regulation of AmVit2 at 24 hpt, but a strong down-regulation by 72 hpt. Similarly, another study showed that AmVit2 was also down-regulated in the long term, when honey bees were exposed to acaricides such as thymol and coumaphos (Boncristiani et al., 2012). Down-regulation of AmVit2 toward neonicotinoids after $72 \mathrm{~h}$ might have been due to the synergistic effect of metabolite compounds as mentioned before. The decreased AmVit 2 expression caused by neonicotinoid insecticides may have led to the reduction in the length of life observed in the treated bees. This conclusion is supported not only by the results of our survivorship experiments, but also by previous studies that have shown a positive correlation between AmVit2 and lifespan of honey bees (Seehuus et al., 2006; Corona et al., 2007). AmVit2 regulates the production of vitellogenin, the yolk protein in the bee's fat body that acts as an antioxidant agent in insects (Corona et al., 2007). Yolk protein is considered the most important protein in insects because it has multiple functions related to development, longevity, immunity, and general health (Amdam et al., 2003). Thus, the reduction of AmVit2 levels might cause immune senescence (aging) in honey bees (Amdam et al., 2005). In addition to the above, high vitellogenin levels in the body of an insect provides protection to cells against ROS because vitellogenin is a potent antioxidant agent, which enhances cell tolerance to oxidation reaction (Seehuus et al., 2006). Therefore, suppressed or reduced expression of AmVit2 in worker bees may lead to decreased resistance to oxidative stress, and consequently, longevity might be reduced. Contrary to our results, Christen et al. (2016), found that exposure of honey bees to imidacloprid and clothianidin, up-regulated AmVit2. Differences in AmVit2 expression between their study and our study were possibly related to the tissue used for RNA extraction; whole bodies were used in this study whereas in the study by Christen et al. (2016) brains and thoraces were used. Additionally, Christen et al. (2016) exposed foraging bees of unknown ages to the neonicotinoid insecticides ad libitum in sugar syrup, whereas this study used newly emerged bees that were treated once with a single dose of the neonicotinoid insecticide. Uniform protocols are thus needed to make results of studies on the effects of insecticides on gene expression comparable. 
Conversely to the above results, AmVit2 expression did not vary relative to the control when bees were treated orally with carbaryl, but significantly increased by $72 \mathrm{hpt}$ in workers that were treated topically with the insecticide. Increased expression of this gene in topical treatments might be related to the mode of action of carbaryl. Carbaryl kills insects mainly by contact rather than by ingestion. This may have resulted in the upregulation of AmVit2, as a protective mechanism against the action of carbaryl molecules, but it may have taken time for the pesticide to reach the sites of action. The fact that carbaryl did not affect the expression of AmVit2 in oral treatments may have been related to a fast degradation of the insecticide when ingested by the bees; degradation would have reduced carbaryl concentration to a level not high enough to trigger AmVit2 expression.

AmPuf68 exhibited a strong response to all insecticides. The expression of this gene was significantly increased at $24 \mathrm{hpt}$ in response to one insecticide provided orally to the bees (imidacloprid) and to all of them at $72 \mathrm{hpt}$ in bees treated with all insecticides using both application methods. To the best of our knowledge, this study is the first to examine the expression of AmPuf68 in response to insecticides. Previous studies have reported an effect on the regulation of AmPuf68 in bees parasitized by pathogens such as V. destructor (Hamiduzzaman et al., 2012; Koleoglu et al., 2017) or by entomopathogenic fungi (Hamiduzzaman et al., 2012). Parasitism by $V$. destructor mites inhibits AmPuf68 expression, whereas entomopathogenic fungi increase it. Clearly, the expression of AmPuf68 is differentially affected by insecticides compared to how it is affected by some pathogens such as mites, but reflects that of other pathogens such as fungi. It is known that $p U f 68$ regulates mRNA splicing in a subset of genes in D. melanogaster (Van Buskirk and Schumbach, 2002). Thus, the effect of insecticides on the expression of AmPuf 68 could be associated with the regulation of mRNA, increasing its expression, which could result in better protection against xenobionts. Nevertheless, further investigation of the mechanisms that are regulated by AmpUf68 and how they impact honey bee health are warranted.

AmCYP9Q3 regulates the production of detoxification enzymes that metabolize and enhance tolerance of honey bees to pesticides (Claudianos et al., 2006). The results of this study showed significant up-regulation of $A m C Y P 9 Q 3$ as a response to sublethal doses of imidacloprid, clothianidin, and carbaryl, for oral and contact applications, particularly at $72 \mathrm{hpt}$. Similarly, a high expression of this gene was observed by Mao et al. (2011) when they topically exposed honey bees to $10 \mu \mathrm{g} / \mu \mathrm{l}$ of the pyrethroid tau-fluvalinate, and De Smet et al. (2017) also found the gene to be up-regulated in bees exposed orally to imidacloprid for 40 days. Considering that imidacloprid's half-life ranges between 4.5 and $5 \mathrm{~h}$ in bees exposed to a concentration of $20 \mathrm{ppm}$ to $50 \mathrm{ppm}$ (Suchail et al., 2003; the doses used in this study fall within this range), the up-regulation of $A m C Y P 9 Q 3$ by secondary metabolites, such as oleofin and 5-hydroxymidacloprid, cannot be discarded. The results of this study also revealed that routes of exposure had an influence on the expression of AmCYP9Q3. In oral applications, $A m C Y P 9 Q 3$ was up-regulated at 24 and $72 \mathrm{hpt}$ responding to all insecticides. By comparison, in contact applications, the up-regulation of $A m C Y P 9 Q 3$ was delayed until $72 \mathrm{hpt}$ for all insecticides. There are two factors that might explain these results. First, a high level of expression of $A m C Y P 9 Q 3$ is common in the midgut compared to the hemolymph of honey bees (Claudianos et al., 2006). The higher concentration of the insecticide in the midgut of bees treated orally, might have accelerated the response of this gene to the chemicals. Second, the ingestion route makes it faster for the insecticides to reach the sites of action than when the product is applied topically, resulting in a faster activation of the gene. In topical applications, wax, lipid, and lipoprotein layers in the cuticle of the insects might have slowed down the penetration of the insecticides, taking longer to reach their sites of action. This would have delayed the response of $A m C Y P 9 Q 3$. The increase in expression of this gene caused by all insecticides suggests that the bees were able to activate detoxification mechanisms.

\section{CONCLUDING REMARKS}

Honey bees are not a target for agricultural pesticides, yet, they are constantly exposed to sublethal doses of them by different means. This study demonstrated that sublethal doses of neonicotinoid and carbamate insecticides significantly shorten the life span of honey bees and induce or inhibit the expression of immune, health and detoxification related genes of these insects, which could have negative or beneficial implications. Regardless of the benefits or negative effects in the exposed insects, responses of the different systems associated with these genes are costly and may end up being traded off against other physiological functions, such as reduction in the host's lifespan, susceptibility to pathogens or productivity. Further studies are warranted to better understand how sublethal exposure to neonicotinoid and carbamate insecticides impact biological pathways and the physiological costs incurred by the affected bees. 


\section{ACKNOWLEDGEMENTS}

We thank Paul Kelly and David Stotesbury for their assistance in managing the experimental colonies and for providing bees for the experiments. This study was partially funded by a grant from the Ontario Ministry of Agriculture, Food and Rural Affairs to EG.

\section{REFERENCES}

Alaux, C, Brunet, JL, Dussaubat, C, Mondet F, et al. (2010). Interactions between Nosema microspores and a neonicotinoid weaken honeybees (Apis mellifera). Environ. Microbiol. 12 (3): 774-782. https://doi.org/10.1111/j.1462-2920.2009.02123.x

Aliouane Y, El Hassani AK, Gary V, Armengaud C, et al. (2009). Subchronic exposure of honeybees to sublethal doses of pesticides: effects on behavior. Environ. Toxicol. Chem. 28 (1): 113-122. https://doi.org/10.1897/08-110.1

Amdam GV, Simoes ZL, Guidugli KR, Norberg K, et al. (2003). Disruption of vitellogenin gene function in adult honeybees by intraabdominal injection of double-stranded RNA. BMC Biotechnol. 3: 1-8.

Amdam GV, Simoes ZL, Hagen A, Norberg K, et al. (2004). Hormonal control of the yolk precursor vitellogenin regulates immune function and longevity in honeybees. Exp. Gerontol. 39 (5): 767-773. https://doi.org/10.1016/j.exger.2004.02.010

Amdam, GV, Aase ALT, Seehuus S, Fondrk MK, et al. (2005). Social reversal of immunosenescence in honey bee workers. Exp. Geronotol. 40 (12): 939-947. https://doi.org/10.1016/j.exger.2005.08.004

Blacquière T, Smagghe G, Van Gestel CA and Mommaerts V (2012). Neonicotinoids in bees: a review on concentrations, side-effects and risk assessment. Ecotoxicology 21 (4): 973-992. https://doi.org/10.1007/s10646-012-0863-X

Boncristiani H, Robyn U, Ryan S, Jay D, et al. (2012). Direct effect of acaricides on pathogen loads and gene expression levels in honey bees Apis mellifera. J. Insect Physiol. 58 (5): 613-620. https://doi.org/10.1016/j.jinsphys.2011.12.011

Broderick NA, Welchman DP and Lemaitre B (2009). Recognition and response to microbial infection in Drosophila. In: Insect Infection and Immunity: Evolution, Ecology, and Mechanisms (Rolff J and Reynolds SE eds). Oxford University Press, Oxford, 13-29. https://doi.org/10.1093/acprof:oso/9780199551354.003.0002

Chen GJ, Jin S and Goodwin PH (2000). An improved method for the isolation of total RNA from Malva pusilla tissues infected with Colletotrichum gloeosporioides. J. Phytopath. 148 (1): 57-60. https://doi.org/10.1046/j.1439-0434.2000.00470.x

Christen V, Mittner F and Fent K (2016). Molecular effects of neonicotinoids in honey bees (Apis mellifera). Environ. Sci. Technol. 50 (7): 4071-4081. https://doi.org/10.1021/acs.est.6b00678

Claudianos C, Ranson H, Johnson RM, Biswas S, et al. (2006). A deficit of detoxification enzymes: pesticide sensitivity and environmental response in the honeybee. Insect Mol. Biol. 15: 615-636.

Collison EJ, Hird H, Tyler CR and Cresswell JE (2017). Effects of neonicotinoid exposure on molecular and physiological indicators of honey bee immunocompetence. Apidologie 1-13. https://doi.org/10.1007/s13592-017-0541-3

Corona M., Velarde RA, Remolina S, Moran-Lauter A, et al. (2007). Vitellogenin, juvenile hormone, insulin signaling, and queen honey bee longevity. Proc. Natl. Acad. Sci. U.S.A. 104 (17): 7128-7133. https://doi.org/10.1073/pnas.0701909104

De Smet L, Hatjina F, Ioannidis P, Hamamtzoglou A, et al. (2017). Stress indicator gene expression profiles, colony dynamics and tissue development of honey bees exposed to sub-lethal doses of imidacloprid in laboratory and field experiments. PloS One 12 (2): e0171529. https://doi.org/10.1371/journal.pone.0171529 
Sub-lethal doses of neonicotinoid and carbamate insecticides reduces the lifespan and alters the expression of immune, health and detoxification related genes of honey bees (Apis mellifera)

Dean JD, Goodwin PH and Hsiang T (2002). Comparison of relative RT-PCR and northern blot analyses to measure expression of $\beta-1,3-$ glucanase in Nicotiana benthamiana infected with Colltotrichum destructivum. Plant Mol. Biol. Rep. 20 (4): $347-356$. https://doi.org/10.1007/bf02772122

Decourtye A, Devillers J, Cluzeau S, Charreton M, et al. (2004). Effects of imidacloprid and deltamethrin on associative learning in honeybees under semi-field and laboratory conditions. Ecotoxicol. $\quad$ Environ. $\quad$ Saf. $57 \quad$ (3): $410-419$. https://doi.org/10.1016/j.ecoenv.2003.08.001

Erler S, Popp M and Lattorff MG (2011). Dynamics of immune system gene expression upon bacterial challenge and wounding in a social insect (Bombus terrestris). PLoS One 6 (3): e18126. https://doi.org/10.1371/journal.pone.0018126

Evans JD (2006). Beepath: An order quantitative-PCR array for exploring honey bee immunity and disease. J. of Invert. Path. 93 (2): 135 139. https://doi.org/10.1016/j.jip.2006.04.004

Guzman-Novoa E (2016). Colony collapse disorder and other threats to honey bees. In: One Health Case Studies: Addressing Complex Problems in a Changing World. (Cork S, Hall DC, Liljebjelke K eds). 5M Publishing Ltd, Sheffielf: 204-216.

Hamiduzzaman MM, Sinia A, Guzman-Novoa E and Goodwin PH (2012). Entomopathogenic fungi as potential biocontrol agents of the ecto-parasitic mite, Varroa destructor, and their effect on the immune response of honey bees (Apis mellifera L.). J. Invertebr. Pathol. 111 (3): 237-243. https://doi.org/10.1016/j.jip.2012.09.001

James R and Xu J (2011). Mechanisms by which pesticides affect insect immunity. J. of Invert. Path. 109(2): 175-82. https://doi.org/10.1016/j.jip.2011.12.005

Johnson RM, Ellis MD, Mullin CA and Frazier M (2010). Pesticides and honey bee toxicity-USA. Apidologie 41 (3): 312-331. https://doi.org/10.1051/apido/2010018

Kevan PG, Guzman E, Skinner A and Van Englesdorp D (2007). Colony collapse disorder in Canada: Do we have a problem? Hive Lights 20: 14-16. https://doi.org/10.1036/1097-8542.149250

Koleoglu G, Goodwin PH, Reyes-Quintana M, Hamiduzzaman MM, et al. (2017). Effect of Varroa destructor, wounding and varroa homogenate on gene expression in brood and adult honey bees. PLoS One 12 (1): e0169669. https://doi.org/10.1371/journal.pone.0169669

López J H, Krainer S, Engert A, Schuehly W, et al. (2017). Sublethal pesticide doses negatively affect survival and the cellular responses in American foulbrood-infected honeybee larvae. Scientific reports 7: 40853. https://doi.org/10.1038/srep40853

Mackenzie KE and Winston ML (1988). The effects of sub-lethal exposure to diazinon, carbaryl and resmethrin on longevity and foraging in Apis mellifera L. Apidology 20 (1): 29-40. https://doi.org/10.1051/apido:19890104

Mao W, Schuler MA and Bernbaum MR (2011). CYP9Q-mediated detoxification of acaricides in the honey bee (Apis mellifera). Proc. Natl. Acad. Sci. U.S.A. 108 (31): 12657-12662. https://doi.org/10.1073/pnas.1109535108

Mullin CA, Frazier JL, Ashcraft S, Simonds R, et al. (2010). High levels of miticides and agrochemicals in North American apiaries: Implications for honey bee health. PLoS One 5 (3): e9754. https://doi.org/10.1371/journal.pone.0009754

Nauen R, Tietjen K, Wagner K and Elbert A (1998). Efficacy of plant metabolites of imidacloprid against Myzus persicae and Aphis gossypii (Homoptera: Aphididae). Pest Manag. Sci. 52 (1): 53-57. https://doi.org/10.1002/(sici)1096-9063(199801)52:1\%3C53::aidps621\%3E3.0.co;2-6

Potts SG, Biesmeijer J C, Kremen C, Neumann P, et al. (2010). Global pollinator declines: Trends, impacts and drivers. Trends Ecol. Evol. 25 (6): 345-353. https://doi.org/10.1016/.t.tree.2010.01.007 
Seehuus SC, Norberg K, Gimsa U, Krekling T, et al. (2006). Reproductive protein protects functionally sterile honey bee workers from oxidative stress Proc. Natl. Acad. Sci. U.S.A. 103 (4): 962-967. https://doi.org/10.1073/pnas.0502681103

Siede R, Faust L, Meixner MD, Maus C, Grünewald B and Büchler R (2017). Performance of honey bee colonies under a long-lasting dietary exposure to sublethal concentrations of the neonicotinoid insecticide thiacloprid. Pest Manag. Sci. 73 (3): 1334-1344. https://doi.org/10.1002/ps.4547

Simon JY (2014). The toxicology and biochemistry of insecticides. (2nd edn). CRC Press, Boca Raton, USA.

Suchail S, Debrauwer L and Belzunces L (2003). Metabolism of imidacloprid in Apis mellifera. Pest. Manag. Sci. 60: 291-296.

Thompson GJ, Yockey H, Lim J and Oldroyd, BP (2007). Experimental manipulation of ovary activation and gene expression in honey bee (Apis mellifera) queens and workers: testing hypotheses of reproductive regulation. J. Exp. Zool. A Ecol. Integr. Physiol. 307: 600-610. https://doi.org/10.1002/jez.415

Van Buskirk C and Schüpbach T (2002). Half pint regulates alternative splice site selection in Drosophila. Dev. Cell 2 (3): 343-353. https://doi.org/10.1016/s1534-5807(02)00128-4

Van der Sluijs JP, Simon-Delso N, Goulson D, Maxim L, et al. (2013). Neonicotinoids, bee disorders and the sustainability of pollinator services. Current opinion in environmental sustainability 5 (4): 293-305. https://doi.org/10.1016/j.cosust.2013.05.007

Wang S, Wagner EJ and Mattox W (2013). Half Pint/Puf68 is required for negative regulation of splicing by the SR factor Transformer2. RNA Biology 10 (8): 1396-1406. https://doi.org/10.4161/rna.25645

Williamson SM, Willis SJ and Wright GA (2014). Exposure to neonicotinoids influences the motor function of adult worker honeybees. Ecotoxicology 23 (8): 1409-1418. https://doi.org/10.1007/s10646-014-1283-X

Wu JY, Anelli CM and Sheppard WS (2011). Sub-lethal effects of pesticide residues in brood comb on worker honey bee (Apis mellifera) development and longevity. PloS One 6 (2): e14720. https://doi.org/10.1371/journal.pone.0014720 